\title{
Cognitive and neuroimaging profile of a Brazilian family with CADASIL
}

\author{
Júlio César Vasconcelos da Silva', Emerson L. Gasparetto², Charles André3
}

\begin{abstract}
Cerebral autosomal dominant arteriopathy with subcortical infarcts and leukoencephalopathy (CADASIL) is an inherited small vessel disease leading to small infarcts and subcortical vascular dementia. This study presents results from the neuropsychological and neuroimaging evaluation of functionally autonomous individuals of a Brazilian family with CADASIL. The causal mutation was confirmed in four family members. Seven individuals from two generations were evaluated using the CERAD battery and additional neuropsychological tests and were submitted (6 individuals) to magnetic resonance imaging (MRI) of the brain with specific protocols for white matter lesion quantification. Apraxic changes and fast progression over nine months (neuropsychological reevaluation of 6 individuals) were found in many individuals. The MRI study suggests greater involvement of frontal lobes in more severely affected individuals. Even functionally independent individuals may exhibit significant neuropsychological and neuroimaging changes. Apraxia, little commented on in literature, and rapidly progressive cognitive changes were found in this group.
\end{abstract}

Key words: CADASIL, stroke, neuropsychology, cognition, vascular dementia, MRI.

\section{Perfil cognitivo e neuroimagem de uma família brasileira com CADASIL}

\section{RESUMO}

Arteriopatia cerebral autossômica dominante com infartos subcorticais e leucoencefalopatia (CADASIL) é uma doença hereditária de pequenos vasos levando a pequenos infartos e demência vascular subcortical. Este estudo apresenta resultados da avaliação neuropsicológica e de neuroimagem de indivíduos funcionalmente autônomos de uma família brasileira com CADASIL. Sete indivíduos de duas gerações foram avaliados através da bateria CERAD e testes neuropsicológicos adicionais e seis foram submetidos a ressonância magnética (RM) do encéfalo com protocolos específicos para a quantificação de lesão em substância branca. Alterações apráxicas e rápida progressão ao longo de nove meses foram encontradas em vários indivíduos. O estudo de RM sugeriu maior envolvimento dos lobos frontais em indivíduos mais severamente afetados. A mutação causal foi confirmada em quatro membros da família. Mesmo indivíduos funcionalmente independentes podem apresentar significativas alterações neuropsicológicas e de neuroimagem. Apraxia, menos comentada na literatura, e alterações cognitivas rapidamente progressivas foram encontradas neste grupo.

Palavras-chave: CADASIL, acidente vascular cerebral, neuropsicologia, cognição, demência vascular, RM.

\section{Correspondence}

Charles André

Serviço de Neurologia

Hospital Universitário

Clementino Fraga Filho

Av. Prof. Rodolpho Paulo Rocco 255

salas 10 e 36

21941-913 Rio de Janeiro RJ - Brasil

E-mail:dr.charles.andre@gmail.com

Received 22 September 2010

Received in final form 19 February 2011

Accepted 01 March 2011
CADASIL (cerebral autosomal dominant arteriopathy with subcortical infarcts and leukoencephalopathy) is a cerebral arteriopathy caused by mutations in the Notch -3 gene located in chro- mosome 19; approximately $90 \%$ of these mutations are detected in exons 2-6 and $65 \%$ are in exons 3 and $4^{1-3}$. The disease is characterized by recurrent subcortical ischemic attacks, with onset usually in 
middle age and frequently progressing to subcortical dementia. Some individuals, though displaying the genetic mutation, may be asymptomatic or present isolated symptoms, such as migraine with aura, epileptic seizures, transient ischemic attack (TIA), and depression or anxiety ${ }^{4}$.

The onset and evolution of ischemic events may vary greatly within the same family. Recurrence of ischemic attacks causes cumulative motor and cognitive deterioration including psychomotor slowness, reduced attention span, and memory and speech problems ${ }^{4}$. Cognitive changes, which may be observed in some patients long before stroke occurrence, occurs in around $60 \%$ of patents with CADASIL, and psychiatric disturbances in almost $30 \%{ }^{5}$. Neuropsychological evaluation should be extensive, including the use of cognitive test batteries sensitive for the detection of executive dysfunction.

The precise onset of cognitive decline in CADASIL may vary greatly, with location and severity of the lesions as primary determinants ${ }^{6}$. Researchers disagree about the mechanism of this decline. We analyzed the neuropsychological profiles of individuals from one affected family, with a pre-specified re-evaluation after 9 months; and also made a morphological analysis of white matter lesions.

\section{METHOD}

An observational study describing the clinical and neuroradiological aspects of a family with CADASIL was carried on. The research was approved by the Research Ethics Committee of the UFRJ Medical School. Family members were evaluated after informed consent.

Individuals were evaluated twice with a nine-month interval. First, in July 2007, six individuals from this family, all with characteristic MRI alterations, were studied (Fig 1). Four (II-1; II-5; II-9; and II-12) were screened for Notch 3 mutations.

Participants were submitted to the CERAD (consortium to establish a registry for Alzheimer's disease) battery of neuropsychological tests ${ }^{7}$ in addition to the Clock $\mathrm{Test}^{8}$ and Drawing Copy with increasing difficulty (circle, square, triangle, simple stair, flower, complex stair, cube, and bicycle) ${ }^{9}$. Cut off points for each CERAD subtest derived from findings in Brazilian patients with similar formal educational level and mild dementia (CDR 0.5-1) were used in the present study ${ }^{10}$.

Neuropsychological re-evaluation with the same tests was done after nine months (April 2008) in five of the six individuals initially included. One individual (III-4) refused to participate in this second phase of the protocol. An additional family member (II-11) was evaluated at this time and then also nine months later. At this followup evaluation, the Clinical Dementia Rating - CDR (in its Brazilian validated version $)^{11}$ was also calculated.

At the time of follow-up, the five individuals originally studied and II-11 were also submitted to magnetic resonance imaging (MRI) in a 3-Tesla equipment (Magnetrom TRIO, Siemens, Germany) with a 12 channel head matrix coil. Image protocol was the same for all cases and included the following sequences: saggital T1weighted 3D gradient echo images, coronal T2-weighted images, saggital FLAIR 3D sequence, and axial diffusionweighted images. All images were transferred to a work station for storage and processing. FSL software (Oxford, UK) was used in various stages for post-processing and semi-automatic analyses of the white matter lesion loading, using a signal intensity segmentation technique previously described ${ }^{12}$.

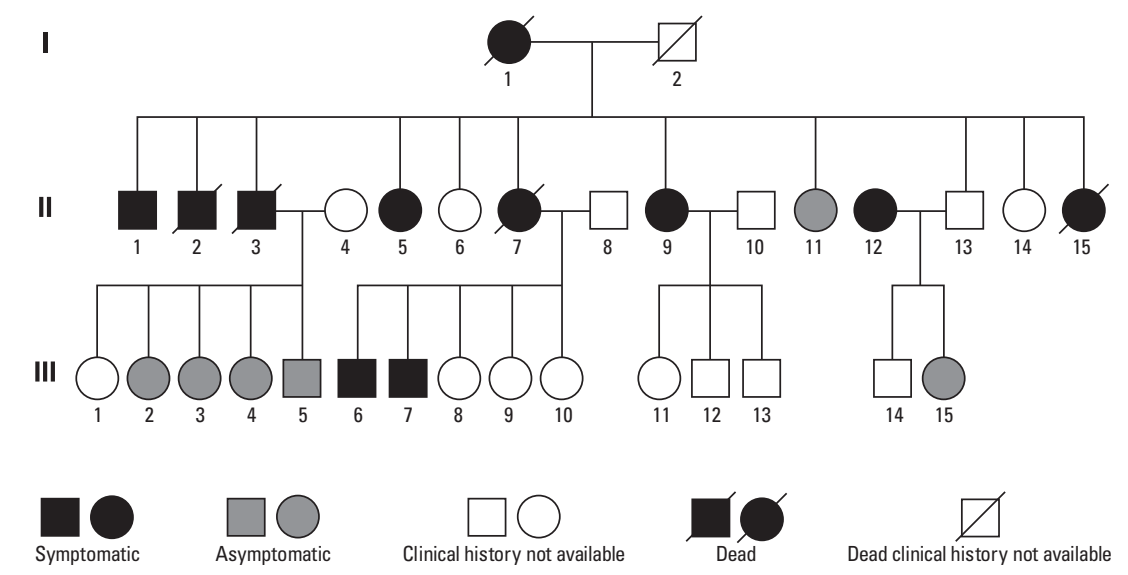

II-1 (52 years old); II-11 (64 years); III-5 (38 years); III-6 (45 years); III-7 (52 years); and II-15 (41 years). III-4 (44 years) left the study in 2007 and patient II-11 (64 years) entered in 2008.

Fig 1. Heredogram of the study family. 


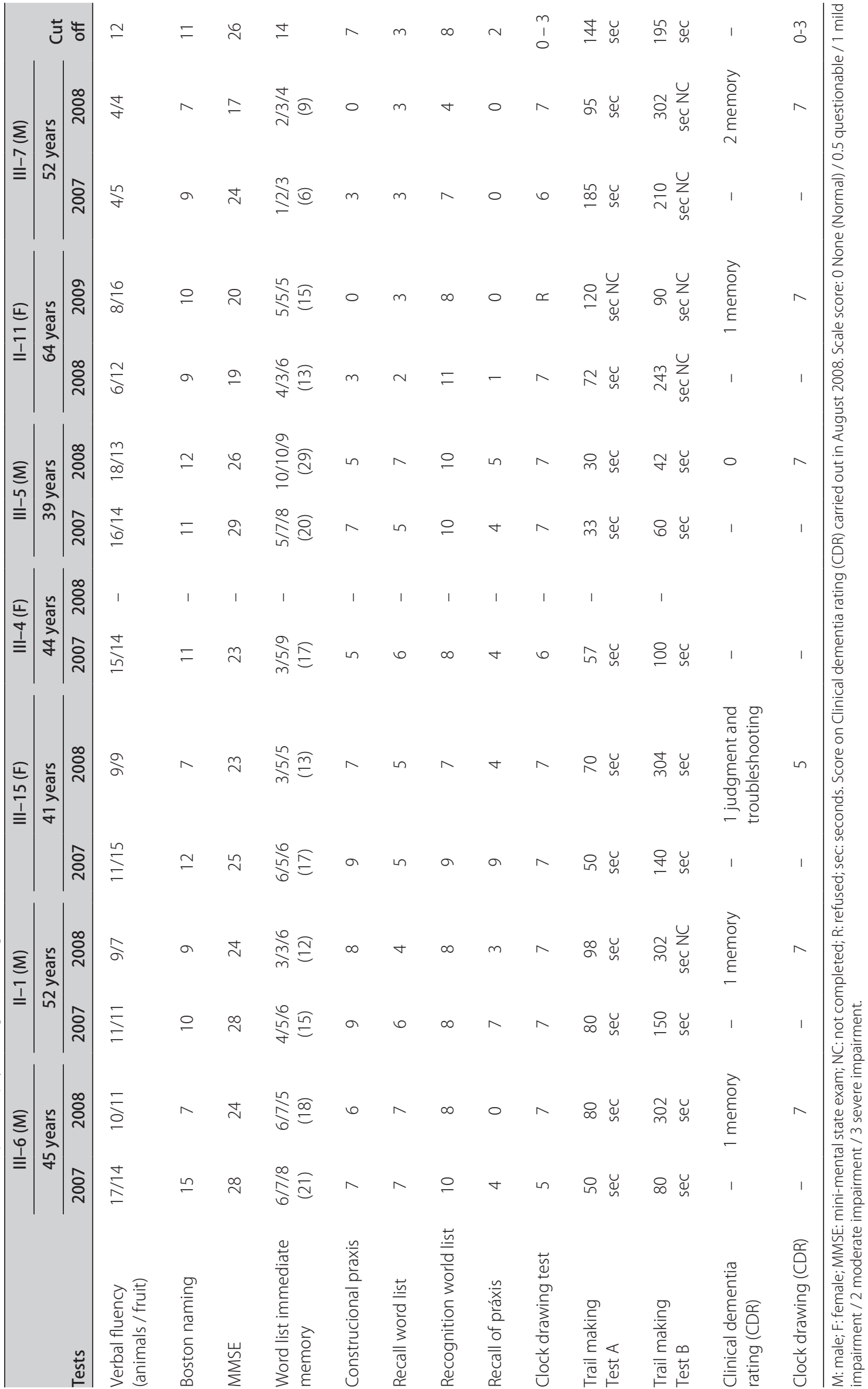




\section{RESULTS}

In all four individuals screened, a mutation of exon 4 (a nucleotidic substitution of an arginine for a cistein in position 153) was found. Some members of the family (Fig 1) already referred previous migraine attacks, hypertension, diabetes, TIA, minor cognitive disturbances, or depression/anxiety that could be related to CADASIL. No formal evaluation of functional independence was made. All individuals however carried out their daily activities without any functional problems (report upon direct questioning of individuals and at least one close relative). All individuals have had 8 or more years of formal education. Cognitive changes were detected in all seven individuals (Table 1). At first evaluation, spontaneous verbal fluency was slightly below cut-off in four. MMSE scores were also reduced in four individuals. Memory impairment was detected in two individuals (word list memory test), while constructive apraxia was present in three individuals.

At follow-up examination, increased cognitive difficulties were found. Five of six reevaluated individuals now exhibited low verbal fluency scores. Object naming was initially only slightly reduced in two individuals, but in five of six at follow-up. Memory was considered ab- normal in three subjects, with reduced spontaneous recall but relative preservation of clued recall.

Cognitive deterioration was found in various domains such as praxis, memory, and language in five of six individuals retested after 9 months. The results of the CDR, indicated that five individuals could already be considered demented at this time (CDR 1 or more).

MRI morphometric analyses in six individuals revealed higher lesion load in frontal and temporal lobes and in deep areas of the brain (Table 2 and Fig 2). The study of proportional lobe lesion volumes suggested a coherent pattern of pathological progression, as in two individuals with smaller total burden (II-11 and III-5) the frontal lobes were relatively preserved (27\% and $32 \%$ of total lesion volumes) than in the other studied members (over 40\%), with greater total lesion volumes.

\section{DISCUSSION}

In the family studied, as in other series, signs of executive dysfunction were salient ${ }^{2,6,13}$. Also, apraxic changes were evident in many individuals. The most significant finding of our study is however the rapid progression of cognitive changes over only 9 months in many (but not all) individuals. Homogenous progression was not found in a
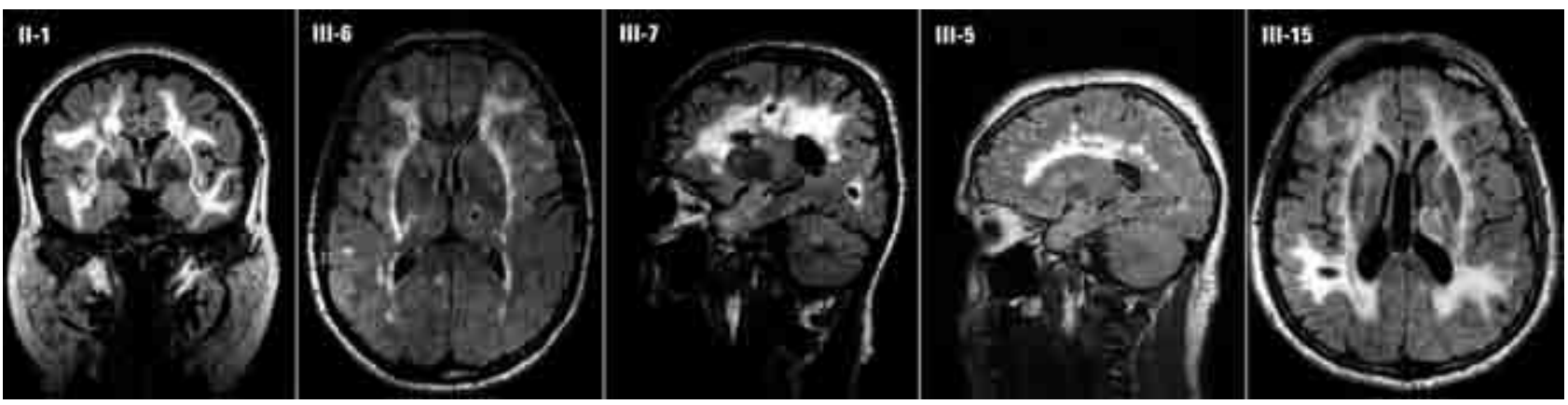

[II-1] Extensive white matter hyperintense areas especially in frontal, temporal, and parietal lobes, and external and internal capsule; right temporal lacunar infarct. [III-6] Less extensive subcortical white matter lesions mainly involving the external capsule; multiple infarcts on the left thalamus and white matter on the right frontal and temporal lobes. [III-7] Hypersignal areas on subcortical periventricular white matter and external capsule, with frontal and parietal-occipital lacunar infarcts. [III-5] Corpus callosus lesions. [III-15] Hyperintense areas on subcortical and periventricular white matter and external capsule; right temporal and basal ganglia lacunes.

Fig 2. MRI images in FLAIR sequences in individuals of the family studied.

Table 2. Relative lesion load in different areas of the brain in MRI from six individuals of the studied family.

\begin{tabular}{|c|c|c|c|c|c|c|c|c|c|c|c|c|}
\hline Individuals & Total volume $\left(\mathrm{cm}^{3}\right)$ & $\%$ total & $\mathrm{FL}$ & $\%$ total & $\mathrm{OL}$ & $\%$ total & PL & $\%$ total & $\mathrm{TL}$ & $\%$ total & Sum & $\%$ dif \\
\hline III-7 & 83.3 & 100.0 & 35.6 & 42.7 & 4.0 & 4.8 & 9.0 & 10.7 & 14.8 & 17.8 & 63.4 & 23.9 \\
\hline III-6 & 166.2 & 100.0 & 70.4 & 42.3 & 2.4 & 1.5 & 14.1 & 8.5 & 33.3 & 20.0 & 120.3 & 27.6 \\
\hline III-15 & 141.7 & 100.0 & 56.9 & 40.2 & 2.2 & 1.6 & 15.4 & 10.9 & 26.6 & 18.8 & 101.1 & 28.6 \\
\hline$\|-11$ & 20.5 & 100.0 & 5.6 & 27.4 & 0.3 & 1.3 & 1.2 & 6.0 & 3.6 & 17.6 & 10.7 & 47.7 \\
\hline$\|-1$ & 287.0 & 100.0 & 119.9 & 41.8 & 3.8 & 1.3 & 26.7 & 9.3 & 57.4 & 20.0 & 207.8 & 27.6 \\
\hline|| $\mid-5$ & 19.8 & 100.0 & 6.3 & 31.9 & 0.6 & 2.9 & 1.7 & 8.6 & 2.7 & 13.79 & 11.32 & 42.8 \\
\hline
\end{tabular}

FL: frontal lobes; OL: occipital lobes; PL: parietal lobes; TL: temporal lobes; $\%$ total: percentage of total lesion volume; \% dif: percentage of total lesion volume outside of areas shown. 
cross-sectional neuropsychological study carried out over two years ${ }^{14}$. Taken together, results from other studies ${ }^{14-16}$ and ours attest significant differences in progression patterns between affected individuals and families.

Cerebral lesion load and cognitive deficit are not linearly related in CADASIL. This variability is clearly demonstrated in the present study, where all affected individuals were functionally independent despite significant lesion burdens. Additional and not well studied genetic and personal factors combine with the mutation effects to determine specific deficits and final functional compromise in any individual.

Apraxic symptoms, little commented in specialized literature, were present in various members of the studied family. Aggression to subcortical structures is implicated in the pathogenesis of apraxia ${ }^{17,18}$. Parietofrontal circuits and their subcortical connections are involved in the sensorimotor integration during movement. Lesions of these structures are associated with ideomotor apraxia ${ }^{19}$.

Many factors may contribute to differences in deterioration speed between series. Epigenetics factors could be mentioned ${ }^{20}$, but also genetic diversity among individuals from different countries and cohorts ${ }^{21} 22$.

The relationship between MRI lesion patterns and cognitive state in patients with CADASIL is still under study $^{14,23-26}$. It has been suggested ${ }^{24,27}$ that cognitive impairment in CADASIL is related to the accumulation of lacunar infarts and increase in ventricular volume but not to brain atrophy. Our small series is inadequate to investigate the correlation between clinical and pathological severity, and further studies addressing this question are clearly needed.

In CADASIL studies evaluating differences in regional lesion load, the temporal lobes and regions such as the external capsule usually exhibit higher scores of white matter change $\mathrm{e}^{21,28}$. Hyperintensity of the temporal lobe and the involvement of the external capsule and corpus callosus seen on MRI seem to be markers for CADASIL and can aid in diagnosing the disease $\mathrm{e}^{21}$. Our own data indicate a greater lesion load in temporal and frontal lobes. Studies evaluating regional differences in lesion load could possibly become specially relevant in future therapeutical trials ${ }^{29}$.

In conclusion, a family with important subclinical cognitive impairment but no significant functional deficits at first evaluation is presented. Apraxic changes and rapid deterioration in a relatively short period are prominent features in many members of this family. Neuroimaging exams revealed significant lesion loads in frontal and temporal lobes and in deep brain regions. Our data also suggest that progressive accumulation of frontal lobe white matter changes can be related to worse cognitive performance.

\section{REFERENCES}

1. Tournier-Lasserve E, Joutel A, Melki J, et al. Cerebral autosomal dominant arteriopathy with subcortical infarcts and leukoencephalopathy maps to chromosome 19q12. Nat Genet 1993;3:256-259.

2. Dichgans M. CADASIL: a monogenic condition causing stroke and subcortical vascular dementia. Cerebrovasc Dis 2002;13(Suppl 2):S37-S41.

3. Joutel A, Corpechot C, Ducros A, et al. Notch-3 mutations in CADASIL, a hereditary adult-onset condition causing stroke and dementia. Nature 1996;383:707-710.

4. Chabriat H. Vascular leukoencephalopathies and dementia. Rev Neurol 1998;154(Suppl 2):S85-S90.

5. Caeiro L, Ferro JM. Cognitive profile in CADASIL patients. J Neurol Neurosurg Psychiatry 2006;77:144-145.

6. Buffon F, Porcher R, Hernandez K, et al. Cognitive profile in CADASIL. J Neurol Neurosurg Psychiatry 2006;77:175-180.

7. Morris JC, Heyman A, Mohs RC, et al. The Consortium to Establish a Registry for Alzheimer's Disease (CERAD) Part I. Clinical and neuropsychological assessment of Alzheimer's disease. Neurology 1989;39:1159-1165.

8. Freedman M, Leach L, Kaplan E, et al. Clock Drawing: a neuropsychological assessment. New York, NY: Oxford University Press; 1994:182.

9. Barbizet J, Duizabo P. Manual de Neuropsicologia. São Paulo: Ed. Masson do Brasil; 1985:158.

10. Bertolucci PHF, Okamoto IH, Toniolo-Neto J, Ramos LR, Brucki SMD. Desempenho da população brasileira na bateria neuropsicológica do Consortium to Establish a Registry for Alzheimer's Disease (CERAD). Rev Psiq Clin 1998;25:80-83.

11. Montaño MBMM, Ramos LR. Validity of the Portuguese version of Clinical Dementia Rating. Rev Saúde Pública 2005;39:1-5.

12. Smith SM, Jenkinson M, Woolrich MW, et al. Advances in functional and structural MR image analysis and implementation as FSL. Neurolmage 2004; 23(Suppl 1):S208-S219.

13. Taillia H, Chabriat $H$, Kurtz $A$, et al. Cognitive alterations in non-demented CADASIL patients. Cerebrovasc Dis 1998;8:97-101.

14. Trojano L, Ragno M, Manca A, Caruso G. A kindred affected by cerebral autosomal dominant arteriopathy with subcortical infarcts and leukoencephalopathy (CADASIL). A 2-year neuropsychological follow-up. J Neurol 1998;245:217-222.

15. Chabriat $H$, Vahedi $K$, Iba-Zizen MT, et al. Clinical spectrum of CADASIL: a study of 7 families: cerebral autosomal dominant arteriopathy with subcortical infarcts and leukoencephalopathy. Lancet 1995;346:934-939.

16. Dichgans M, Mayer M, Uttner I, et al. The phenotypic spectrum of CADASIL: clinical findings in 102 cases. Ann Neurol 1998;44:731-739.

17. Basso A, Faglioni P, Luzzatti C. Methods in neuroanatomical research and an experimental study of limb apraxia. In: Roy EA (Ed). Neuropsychological studies of apraxia and related disorders. New York: North-Holland 1985;179-202.

18. Paillard J. Apraxia and the neurophysiology of motor control. Philosophical Transactions of the Royal Society of London 1982;198:111-134

19. Leiguarda R, Merello M, Balej J. Apraxia in corfticobasal degeneration. In: Litvan I, Goetz CG, Lan AE (Eds). Corticobasal degeneration and related disorders. Advances in neurology, Philadelphia: Lippincott Williams \& Wilkiins 2000;82:103-121.

20. Jirtle RL, Skinner MK. Environmental epigenomics and disease susceptibility. Nat Rev Genet 2007;8:253-262.

21. Markus HS, Martin RJ, Simpson MA, et al. Diagnostic strategies in CADASIL Neurology 2002;59:1134-1138.

22. Razvi SS, Davidson R, Bone I, Muir KW. The prevalence of cerebral autosomal dominant arteriopathy with subcortical infarcts and leucoencephalopathy (CADASIL) in the west of Scotland. J Neurol Neurosurg Psychiatry 2005;76:739-741.

23. Dichgans M, Filippi M, Bruning R, et al. Quantitative MRI in CADASIL. Correlation with disability and cognitive performance. Neurology 1999; 52:1361-1367.

24. Yousry TA, Seelos K, Mayer M, et al. Characteristic MR lesion pattern and correlation of T1 and T2 lesion volume with neurologic and neuropsychological findings in cerebral autosomal dominant arteriopathy with subcortical infarcts and leukoencephalopathy (CADASIL). Am J Neuroradiol 1999;20:91-100

25. Scheid R, Preul C, Lincke T, et al. Correlation of cognitive status, MRI- and SPECT-imaging in CADASIL patients. Eur J Neurol 2006;13:363-370.

26. Liem MK, Lesnik Oberstein SAJ, Haan J, et al. MRI correlates of cognitive decline in CADASIL: A 7-year followup study. Neurology 2009;72:143-148.

27. Kalaria RN, Ballard C. Overlap between pathology of Alzheimer disease and vascular dementia. Alzheimer Dis Assoc Disord 1999;13 (Suppl 3):S115-S123.

28. O'Sullivan M, Jarosz JM, Martin RJ, Deasy N, Powell JF, Markus HS. MRI hyperintensities of the temporal lobe and external capsule in patients with CADASIL. Neurology 2001;56:628-634.

29. Peters $N$, Holtmannspötter $M$, Opherk $C$, et al. Brain volume changes in CADASIL: a serial MRI study in pure subcortical ischemic vascular disease Neurology 2006;66:1517-1522. 